OPEN ACCESS

Edited by:

Bernd Kaina,

Johannes Gutenberg University

Mainz, Germany

Reviewed by:

Gabriele Multhoff,

Technical University of

Munich, Germany

Heidge Fukumasu,

University of São Paulo, Brazil

${ }^{*}$ Correspondence:

Geovanni Dantas Cassali

cassalig@icb.ufmg.br

tThese authors have contributed equally to this work

Specialty section:

This article was submitted to Molecular and Cellular Oncology,

a section of the journa

Frontiers in Oncology

Received: 29 October 2018

Accepted: 14 June 2019

Published: 03 July 2019

Citation:

dos Reis DC, Damasceno KA

de Campos CB, Veloso ES

Pêgas GRA, Kraemer LR

Rodrigues MA, Mattos MS,

Gomes DA, Campos PP, Ferreira E,

Russo RC and Cassali GD (2019)

Versican and Tumor-Associated

Macrophages Promotes Tumor

Progression and Metastasis in Canine

and Murine Models of Breast

Carcinoma. Front. Oncol. 9:577.

doi: 10.3389/fonc.2019.00577

\section{Versican and Tumor-Associated Macrophages Promotes Tumor Progression and Metastasis in Canine and Murine Models of Breast Carcinoma}

\author{
Diego Carlos dos Reis ${ }^{1,2}$, Karine Araújo Damasceno ${ }^{3}$, Cecília Bonolo de Campos ${ }^{1}$, \\ Emerson Soares Veloso ${ }^{1}$, Gabriela Rafaela Arantes Pêgas ${ }^{1}$, Lucas Rocha Kraemer ${ }^{2}$, \\ Michele Angela Rodrigues ${ }^{1}$, Matheus Silvério Mattos ${ }^{2}$, Dawidson Assis Gomes ${ }^{4}$, \\ Paula Peixoto Campos ${ }^{1}$, Enio Ferreira ${ }^{1}$, Remo Castro Russo ${ }^{2 t}$ and \\ Geovanni Dantas Cassali ${ }^{1 *+}$
}

\begin{abstract}
${ }^{1}$ Department of General Pathology, Institute of Biological Sciences, Universidade Federal de Minas Gerais, Belo Horizonte, Brazil, ${ }^{2}$ Laboratory of Pulmonary Immunology and Mechanics, Department of Physiology and Biophysics, Institute of Biological Sciences, Universidade Federal de Minas Gerais, Belo Horizonte, Brazil, ${ }^{3}$ Oswaldo Cruz Foundation, Gonçalo Moniz Institute, Salvador, Brazil, ${ }^{4}$ Department of Biochemistry and Immunology, Institute of Biological Sciences, Universidade Federal de Minas Gerais, Belo Horizonte, Brazil
\end{abstract}

Versican and tumor-associated macrophages (TAMs) are involved in growth and metastases in several cancers. Here, we investigated the potential role of versican, a matrix proteoglycan, and its correlation with TAMs infiltrates in different stages of two different breast cancer models: spontaneous canine mammary gland carcinomas and the murine 4T1 breast cancer model. The stromal versican expression was correlated with TAMs accumulation in tumors with an advanced stage from spontaneous canine mammary carcinoma samples. Versican expression in mice, identified in late stages of tumor progression, was associated to a high number of peri-tumoral infiltrating TAMs. Indeed, TAMs were related to a pro-inflammatory and pro-angiogenic state in the primary tumor. Furthermore, TAMs accumulation was related to versican expression in the lungs and an increased number of pulmonary metastatic nodules with pulmonary mechanical dysfunction, which was due to leukocyte influx in the airways and elevated growth factor levels in the microenvironment. Thus, we suggest that versican and TAMs as attractive targets for breast cancer therapy.

Keywords: breast cancer, angiogenesis, lung metastasis, versican, tumor-associated macrophages

\section{INTRODUCTION}

The tumor microenvironment has been increasingly recognized as an important participant of tumor progression $(1,2)$ and metastasis $(3)$. As a result, there is an escalating interest in studies involving components of the extracellular matrix (ECM) and its interaction with neoplastic, stromal, endothelial and immune cells, as well fibroblasts (4-6). Interaction between ECM and 
inflammatory cells, mostly macrophages have been shown to be involved in the progression and development of breast cancer metastasis (7).

Breast cancer is the most common cancer in women worldwide and the second leading cause of cancer-related deaths in women (8). Generally, localized diseases are largely curable, whereas metastatic or recurrent diseases imply in poor prognosis. Metastatic disease may be found in broad range of organs and tissues, such as the bone, brain, liver and lungs (9). Lung metastasis may affect the pulmonary microenvironment and its function. Indeed, reduced lung function is an important risk factor for lung cancer, increasing the surgical risk of patients with advanced lung cancer, in which the low forced expiratory volume (FEV1) is strongly associated with mortality of non-small cell lung cancer patients (10).

Versican is an extracellular matrix proteoglycan that is highly expressed in early development stages, with low expression remaining in adults, increasing dramatically following tissue inflammation (11, 12) and neoplastic diseases (13). In cancer, versican has been identified as a modulator of cell adhesion, proliferation, apoptosis, angiogenesis, invasion, and metastasis (14-16). Recent studies also have been shown that versican interacts with monocytes/macrophages promoting their activation, migration, and production of growth factors. By activating TLR2:TLR6 complexes from tumor-associated macrophages (TAMs), versican induces the production of proinflammatory and pro-tumoral cytokines and chemokines, such as tumor necrosis factor- $\alpha$ (TNF- $\alpha$ ), tumor growth factor$\beta 1$ (TGF- $\beta 1$ ), vascular endothelial growth factor (VEGF), and CC chemokine ligand 2 (CCL2), as well as versican production (17-20).

Tumor-associated macrophages (TAMs) are found in different tumor types (21-23) and are related with poor prognosis (21, 24-26). TAMs closely resemble the M2-polarized macrophages, which promote tumor growth and progression by several mechanisms, including the secretion of pro-tumoral growth factors and inhibitory cytokines. In fact, TAMs also induce angiogenesis, reduce effector functions of tumor-infiltrating lymphocytes, and enhance $\mathrm{T}$ regulatory lymphocyte (Treg) expansion (27). The relationship between versican and TAMs in breast cancer development is still poorly understood. Therefore, the aim of this study was to characterize the expression of versican and TAMs in spontaneous primary canine mammary gland carcinomas and in the 4T1 mice model of breast cancer, further investigating their role during primary cancer progression and metastasis development in the context of breast cancer.

\section{MATERIALS AND METHODS}

\section{Canine Mammary Tumors Samples}

In total, 108 cases of canine mammary tumors were selected from the archives of the Laboratory of Comparative Pathology of the Federal University of Minas Gerais (UFMG). The samples derived from female dogs of different breeds and ages, which had undergone surgical excision of the mammary gland neoplasm. The neoplasms were categorized according to the World Health
Organization (WHO) classification scheme for canine mammary tumors (28) incorporating updated classification proposals (29). Histological grade was established according to the Nottingham system (30). All tumors were staged from I to $\mathrm{V}$ according to Owen (31). All procedures were performed under the guidelines and with the approval of the Ethics Committee in Animal Experimentation (CETEA/UFMG), protocol 219/2009 and $81 / 2013$.

\section{T1 Mice Model of Breast Cancer}

The 4T1 mouse mammary carcinoma was obtained from the American Type Culture Collection (Manassas, USA), and the 4T1 cells were maintained in RPMI 1640 medium supplemented with $10 \%$ fetal bovine serum (Hyclone, Logan, UT, USA). Cell cultures were maintained at $37^{\circ} \mathrm{C}$ in a humidified atmosphere of $5 \% \mathrm{CO}_{2}$.

Female BALB/c mice (16-20 g), with 6-8 week old (specificpathogen-free) were obtained from the Centro de Bioterismo (CEBIO) of the Universidade Federal de Minas Gerais (UFMG), in Brazil. The mice were housed in a ventilated barrier rack (Alesco Indústria e Comércio Ltda, Monte Mor, SP, Brazil) in a temperature-controlled facility on a 12 -h photoperiod. The mice were given food and water ad libitum. Mice were subcutaneously inoculated with $2.5 \times 10^{6} 4 \mathrm{~T} 1$ cells in the right flank. They were anesthetized with a subcutaneous injection of $8.5 \mathrm{mg} / \mathrm{kg}$ of xylazine and $130 \mathrm{mg} / \mathrm{kg}$ of ketamine on the 14th, 21st, and 28th day following tumor inoculation, to perform the assessment of respiratory mechanics and blood sample collection. Assessments of respiratory mechanics were also performed in control mice $(n=8)$. Then, under anesthesia, the tumor bearing-mice and control mice were euthanized and bronchoalveolar lavage (BAL) was performed. Tumor and lung samples were collected, weighted, and processed for biochemical and histological analysis. All research was conducted under a protocol approved (number 262/2012) by an Ethics Committee on Animal Use (CEUA) from the UFMG.

\section{Assessment of Respiratory Mechanics}

While maintaining spontaneous breathing under anesthesia, the mice were tracheostomized, placed in a body plethysmograph and connected to a computer-controlled ventilator (Forced Pulmonary Maneuver System ${ }^{\circledR}$, Buxco Research Systems ${ }^{\circledR}$, Wilmington, North Carolina USA) as previously described by Russo et al. (32). The parameters assessed were Forced Vital Capacity (FVC), Functional Residual Capacity (FRC), Residual Volume (RV), Pressure $\times$ Volume curve, Forced Expiratory Volume at $50 \mathrm{~ms}$ (FEV50), Forced Expiratory Volume at $100 \mathrm{~ms}$ (FEV100), Tiffeneau-Pinelli index (FEV50/FVC), Fast Flow Volume curve, Dynamic Compliance (Cdyn), and Lung Resistance ( $\mathrm{Rl})$.

\section{Bronchoalveolar Lavage (BAL) and Lung Preparation}

BAL was performed to obtain leukocytes from the alveolar space. The number of leukocytes was determined by total counts in a Newbauer chamber, with differential counts performed in citospin preparations stained with May-Grunwald-GiemsaLi, as previously described (33). After BAL collection, $5 \mathrm{~mL}$ of 
saline-phosphate buffer (PBS) was administered in the right ventricle so that the pulmonary blood vessels and capillaries were washed. Afterwards, the left lung (single lobe) was collected for histological analysis and the right lung was collected, weighed, and frozen for further processing and analysis of cytokines, chemokines, and N-Acetyl- $\beta$-glucosaminidase (NAG).

\section{Histopathological Analysis}

Primary tumors and lungs were excised and fixed in $10 \%$ neutral buffered formalin ( $\mathrm{pH}$ 7.4) for $48 \mathrm{~h}$ and embedded in paraffin. One $4 \mu \mathrm{m}$-thick sections were obtained and stained with hematoxylin and eosin (H\&E) and examined under light microscopy by two pathologists blinded to the experiment. Neoplastic cellular nodules or aggregates distributed throughout the lung parenchyma or alveolar spaces were considered metastatic lesions. Vascular density was performed on primary tumor slides stained with Gomori's trichrome in five fields (20x objective), as previously described $(33,34)$. Collagen deposition was analyzed with the WCIF ImageJ software (NHI) (http://www. uhnresearch.ca/facilities/wcif/imagej/).

\section{Immunohistochemistry}

Versican immunolabeling was performed in canine and murine tumor sections subjected to heat-induced antigen retrieval with chondroitinase ABC (Proteus vulgaris; Sigma Chemicals) digestion at $37^{\circ} \mathrm{C}$ for $90 \mathrm{~min}$ with $0.5 \mathrm{U} / \mathrm{mL}$ of the enzyme in $0.25 \mathrm{M}$ Tris buffer ( $\mathrm{pH} 8.0$ ) containing $0.18 \mathrm{M}$ sodium chloride and $0.05 \%$ bovine serum albumin (BSA). Next, $0.25 \mathrm{M}$ Tris buffer ( $\mathrm{pH}$ 8.0) containing $0.1 \mathrm{M}$ 6-amino-n-caproic-acid and $5 \mathrm{mM}$ benzamidine hydrochloride was added and the samples were incubated for $30 \mathrm{~min}$ to inhibit protease activity. Murine macrophage immunolabeling was performed in tumor sections subjected to antigen retrieval with pepsin (Merck, Billerica, MA, USA) (100 mg pepsin dissolved in $100 \mathrm{ml} \mathrm{H}_{2} \mathrm{O}$ and $1 \mathrm{ml} \mathrm{HCl} 1 \mathrm{~N}$ ) for $30 \mathrm{~min}$ at $37^{\circ} \mathrm{C}$. Endogenous peroxidase activity was blocked with $3 \%$ hydrogen peroxidase in methanol. Slides were then washed and incubated overnight at $4^{\circ} \mathrm{C}$ with 12C5 (Cambridge, UK) for versican and F4/80 (BM8, Hycult Biotech, Netherlands) for macrophages, both monoclonal antibodies. A polymer detection system was used for the identification of the secondary antibody (ADVANCE HRP-ready to use, DakoCytomation). Diaminobenzidine (DAB) was used as a chromogen and sections were counterstained with Mayer's hematoxylin. Negative controls were obtained by substitution of primary antibody by normal serum. Tissue obtained from a newborn mouse brain and the spleen of Balb/c mice were used as positive controls for versican and macrophages, respectively. Canine macrophages immunolabeling was performed as previously described (34).

Murine macrophages stained by F4/80 were counted by selecting 10 hotspot fields at high magnification (400X). Canine macrophages stained by MAC387 were counted in 5 hotspot fields. Versican expression was evaluated in stromal areas adjacent to the neoplasm semi-quantitatively based on the system of score adapted from Skandalis et al. (35), through the overall percentage of the tissue section stained positive (0-100\%) and the 4-point signal intensity scale, classified as: 1, negative or very weak staining; 2 , weak staining; 3 , moderate staining; and
4, strong staining. Versican expression in neoplastic cells was evaluated considering the same score of intensity and percentage only for the 4T1 tumor model.

\section{Tissue Extraction and Determination of $\mathrm{N}$-acetyl- $\beta-\mathrm{D}$-glucosaminidase Activity and Vascularization}

The infiltration of macrophages was quantified by measuring the levels of the lysosomal enzyme $\mathrm{N}$-acetyl- $\beta$-D-glucosaminidase (NAG) present in the lungs, as previously described (36). One hundred milligrams of primary tumors and the right lung were homogenized and centrifuged with $100 \mathrm{~mL}$ of the supernatant was collected and incubated for $10 \mathrm{~min}$ with p-nitrophenyl-Nacetyl- $\beta$-D-glucosaminide (Sigma). The reaction was stopped with the addition of $0.2 \mathrm{M}$ glycine buffer ( $\mathrm{pH}$ 10.6). Results were expressed as $\mathrm{nmol} / \mathrm{mg}$ of wet tissue. The vascularization extent in tumor samples was assessed by the amount of hemoglobin $(\mathrm{Hb})$ detected in the tissue using the Drabkin method, as described by Ferreira et al. (37).

\section{Immunofluorescence}

Confocal immunofluorescence was performed as previously described, with minor changes (38). Primary antibodies used for immunofluorescence were FITC-conjugated anti-F4/80 (1:150, clone mAb BM8, FITC conjugated, Hycult Biotech, Uden, The Netherlands) and anti-TGF- $\beta 1$ (1:100, polyclonal IgG, Santa Cruz Biotechnology, USA), with Alexa Fluor 647 (1:1,000, Life Technologies) as the secondary antibody. Nuclei were stained with Hoechst dye 33258 ( $1 \mu \mathrm{g} / \mathrm{mL}$, Life Technologies) before coverslip mounting for immunofluorescence and confocal laser scanning microscopy (Zeiss LSM 5 Live, Carl Zeiss, Jena, Germany) (40x).

\section{Enzyme-Linked Immunosorbent Assay (ELISA)}

Primary tumor and right lung samples were homogenized and centrifuged at $4^{\circ} \mathrm{C}$ for $10 \mathrm{~min}$ at $10,000 \mathrm{~g}$. Then, TNF- $\alpha$, TGF- $\beta 1$, VEGF, and CCL2 levels were quantified in primary tumor supernatants and lung homogenates were quantified for CXCL1, CCL2, VEGF, and TGF- $\beta 1$ using the DuoSet ELISA kits (R\&D Systems) in accordance to the manufacturer's instructions, as previously described (32). The results were expressed in picograms per milligram of wet tissue.

\section{Statistical Analysis}

Data are presented as the mean \pm SEM and analyzed by oneway ANOVA, with the differences between groups assessed using the Student-Newman-Keuls post-hoc test. Differences in versican expression in the different stages of tumor progression were evaluated by the Kruskal-Wallis test, with the differences between groups assessed using the Mann-Whitney post-hoc test. Correlations were analyzed by the Spearman test. Graphs and analysis were performed using the GraphPad Prism 5.0 software. Differences were considered statistically significant when $p<0.05$. 

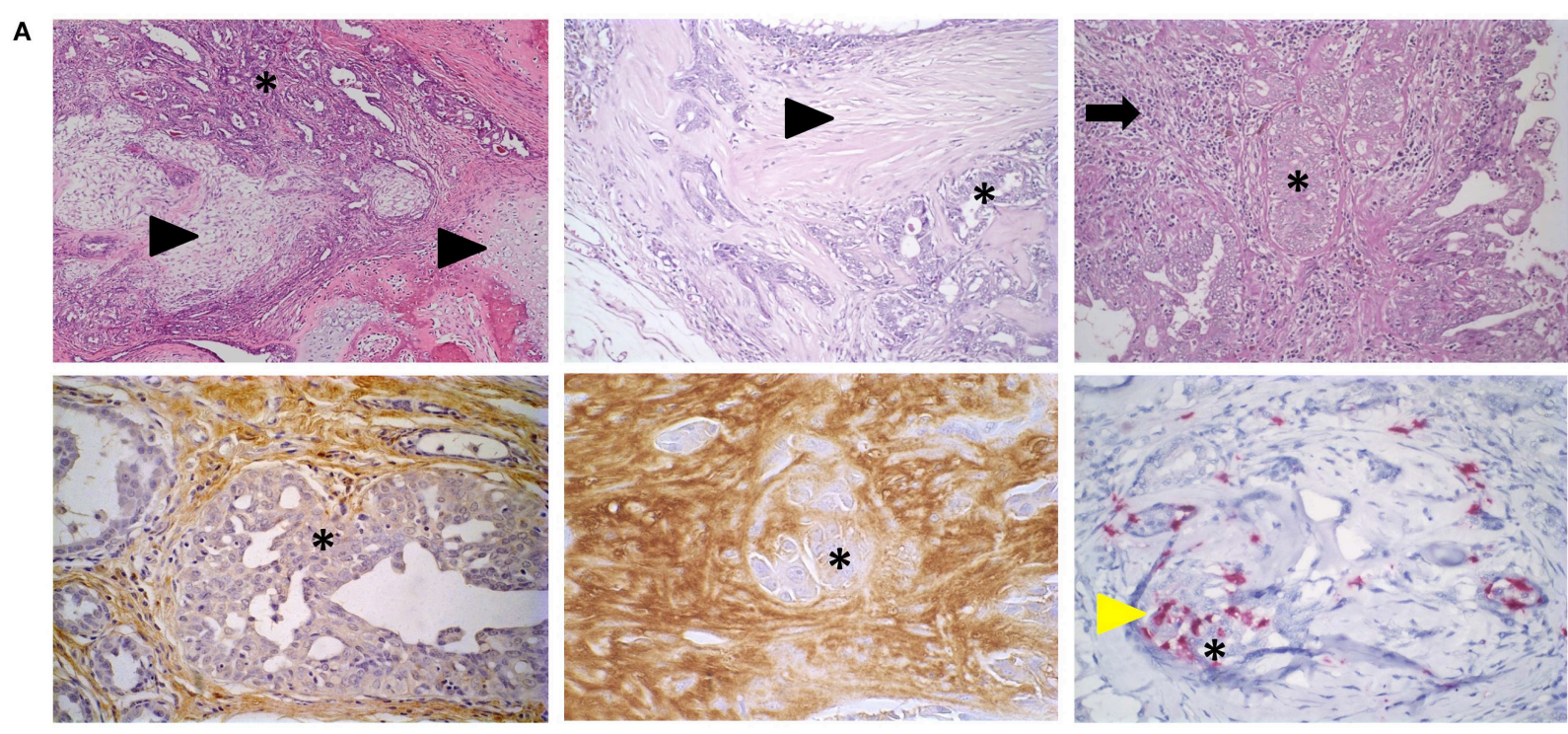

B
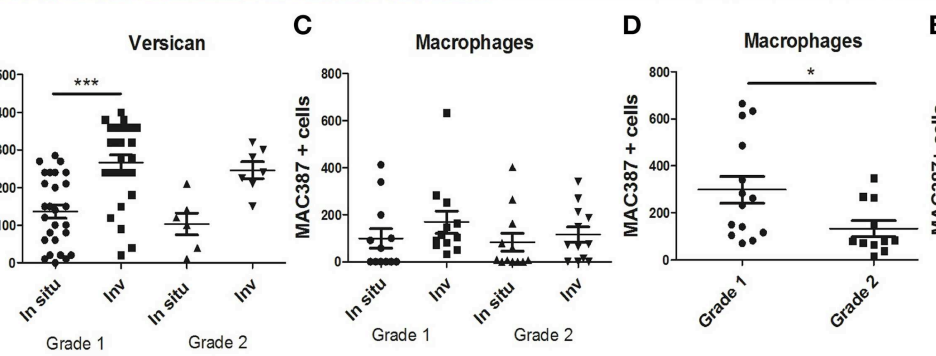

E
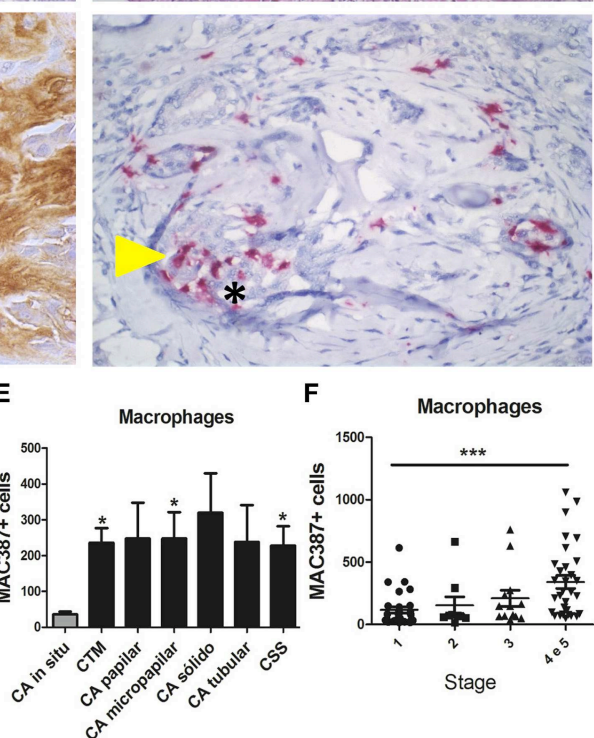

FIGURE 1 | Expression and distribution of versican and TAMs in spontaneous canine mammary carcinomas. Carcinoma in mixed tumors (A) presents epithelial (asterisk) and mesenchymal components (arrowhead) (Upper panel, left and middle images) often surrounded by inflammatory and stromal cells (arrow, upper panel, right image). Immunohistochemistry analysis shows versican expression in the stroma of in situ areas of carcinoma in mixed tumors (bottom panel, left image) and invasive stroma areas (middle image). MAC387+ macrophages (yellow arrowhead, bottom panel, right image) are shown infiltrating around epithelial neoplastic areas of carcinoma in mixed tumors. Versican expression in carcinomas in mixed tumors was increased in invasive areas when compared to in situ areas of grade 1 tumors and in situ areas of grade 2 tumors (B). MAC387+ macrophages quantified by immunohistochemistry were not significantly different across in situ and invasive areas of carcinomas in mixed tumors (C). Grade I carcinoma in mixed tumor presented higher infiltration of MAC387+ macrophages when compared to grade 2 (D). Diverse invasive carcinomas presented higher infiltration of MAC387+ macrophages when compared to in situ carcinomas (E). Stage 4 and 5 tumors presented higher infiltration of MAC387+ macrophages when compared to stage 1 (F). Results are shown as the mean \pm SEM. Kruskal-Wallis test followed by Mann-Whitney test was used to evaluate differences in (C). ${ }^{*} P<0.05,{ }^{* \star *} P<0.001$, respectively.

\section{RESULTS}

\section{Stromal Versican Expression Correlates With TAM Accumulation in Low-Grade and Advanced Stages of Canine Mammary Carcinomas}

We first examined the expression of versican and TAMs infiltration in 108 spontaneous canine mammary neoplasms. Carcinomas in mixed tumor, the most common histological type diagnosed in neoplasm of the mammary gland of dogs (30), were used to evaluate versican expression in in situ and invasive areas (Figure 1A). Versican expression was observed in the stroma, myxoid matrix, and endothelial cells of blood vessels, inflammatory cells, and fibroblasts. Carcinomas in mixed tumors classified as histological grade 1 presented higher versican expression in invasive areas when compared to in situ areas $(P<0.001)$ (Figure 1B). TAMs were evaluated in in situ and invasive areas of diverse histological types (Figure 1C).
Grade 1 tumors presented increased TAMs than grade 2 tumors (Figure 1D). TAM was increased in invasive carcinomas throughout all histological types, with statistical significance in carcinomas in mixed tumors, micropapillary carcinomas, tubular carcinomas, and carcinosarcomas, when compared to in situ carcinomas (Figure 1E). When we categorized these tumors by clinical stage, TAMs infiltration was increased in tumors with advanced clinical stage when compared to early stage tumors (Figure 1F).

\section{Stromal Expression of Versican Is Related With Peritumoral TAM Infiltration and Tumor Progression in Primary Mammary Tumors Using the 4T1 Murine Breast Cancer Model}

We next examined the expression of versican and TAMs infiltration evaluated in the primary tumor and metastatic lung 


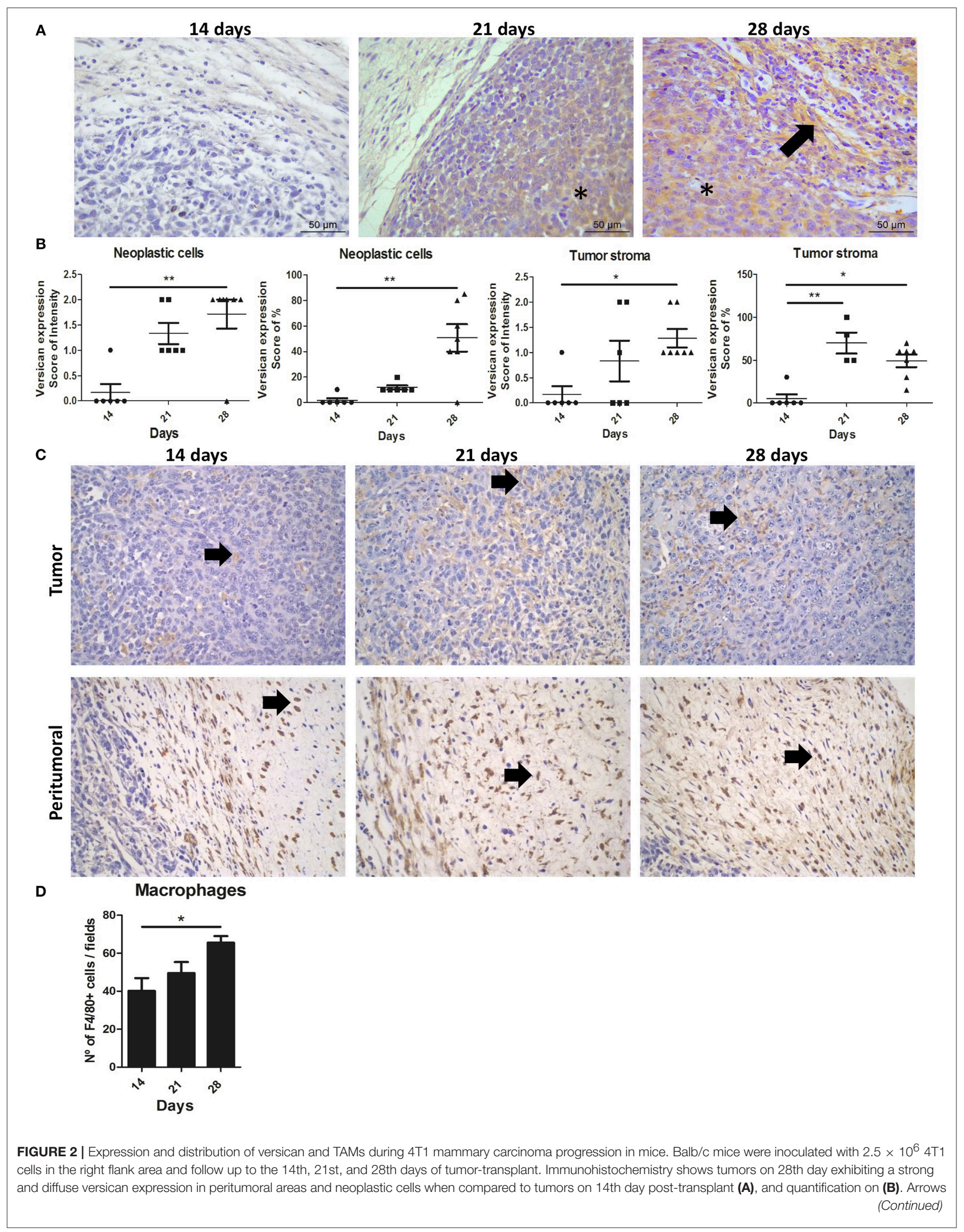


FIGURE 2 | indicate positive staining (brown) in peritumoral areas of the tumor. Asterisks indicate positive staining (brown) in neoplastic cells and tumor stroma Kruskal-Wallis test followed by Dunn's multiple comparisons test was used to evaluate differences among groups. Upper panel shows F4/80+ macrophages in tumoral areas (C). Bottom panel shows F4/80+ macrophages infiltrated in peritumor areas (C). Macrophages quantified through expression of F4/80+ increased in $4 \mathrm{~T} 1$ tumors on day 28 , when compared to tumors on day 14 (D). Results are representative of two experiments and are shown as the mean \pm SEM of seven to eight animals in each group. ${ }^{\star} P<0.05,{ }^{\star \star} P<0.01$, respectively.

of the 4T1 murine model of breast cancer to investigate their role during cancer progression and metastasis. Versican expression was stronger in stromal areas on the 28th day when compared with the 14th day $(P<0.01)$ (Figures $2 \mathrm{~A}, \mathbf{B})$, with an increased percentage of stromal versican staining in tumors on the day 21 st $(P<0.01)$ and 28 th $(P<0.05)$ when compared with the 14 th day. Similarly, in the neoplastic cells, stronger versican staining was found on day 28 when compared to day 14 $(P<0.01)$ (Figures 2A,B).

TAMs infiltration were also predominantly increased and distributed mainly in peritumoral areas on the 28th day when compared with the 14th day $(P<0.01)$ (Figures 2 C,D). A moderate positive correlation was observed between the intensity of versican expression in neoplastic cells and TAMs density ( $r=0.7209, P=0.0036)$ and a moderate positive correlation with the percentage of versican expression and TAMs $(r=0.6299$, $P=0.0158)$. No correlation was observed between stromal versican expression and TAMs (Table 1). Taken together, our data in mice and canine mammary tumors suggest an intrinsic association between stromal versican expression and TAMs infiltration with breast cancer progression and invasion.

\section{Inflammation Is Associated With Stromal Versican Expression and Peritumoral Accumulation of TGF- $\beta 1$-Expressing TAMs During the 4T1 Tumor Development}

We next investigated the contribution of inflammatory mediators in the 4T1 tumor microenvironment and its relationship with versican expression. A progressive increase in the proinflammatory cytokine TNF- $\alpha$, pro-angiogenic protein VEGF, chemokine CCL2, and TGF- $\beta 1$ levels were associated with the 4T1 tumor progression, with increases on days 21 and 28 when compared to day 14 (Figure 3A). A moderate to strong positive correlation was found between versican expression intensity in neoplastic cells and VEGF $(r=0.7600, P=0.0006)$, CCL2 $(r=0.8229, P<0.0001)$, TGF- $\beta 1(r=0.5232, P=0.0311)$, and TNF- $\alpha(r=0.5649, P=0.0226)$ (Table 1). Versican expression percentage in neoplastic cells was positively associated with TNF$\alpha(r=0.6730, P=0.0043), \mathrm{VEGF}(r=0.8489, P<0.0001)$, and CCL2 $(r=0.8853, P=0.0001)$.

A similar trend was observed between stromal versican expression intensity and TNF- $\alpha(r=0.5564, P=0.0204)$, VEGF $(r=0.6297, P=0.0067)$, CCL2 $(r=0.6245$, $P=0.0074)$, and TGF- $\beta 1(r=0.6440, P=0.0053)$. Stromal versican expression was also positively correlated with VEGF $(r=0.5668, P=0.0220)$, CCL2 $(r=0.5878, P=0.0166)$, and TGF- $\beta 1(r=0.5715, P=0.0165)$. Since versican has been previously demonstrated to be up-regulated by TGF- $\beta$ in cancer scenarios $(39,40)$, we investigated if macrophages could be the source of secreted TGF- $\beta 1$. Thus, we co-stained
TGF- $\beta 1$ with a murine macrophage marker, the protein F4/80 (Figure 3B), demonstrating that TGF- $\beta 1$ and F4/80+ cells were predominantly localized in the peritumoral areas and, therefore, that macrophages might be an important source of TGF- $\beta 1$ in the tumor microenvironment. However, other F4/80 negative cells, morphologically classified as spindle-cells resembling fibroblasts, were also found to express TGF- $\beta 1$ (data not shown).

\section{Higher Versican Expression Is Accompanied by Angiogenesis and Tissue Remodeling During the 4T1 Tumor Development}

The 28th day was associated with a higher amount of hemoglobin and blood vessels when compared to the 14th and 21st day $(P<0.05$ and $P<0.001$, respectively) (Figures 4A,B). Interestingly, 4T1 tumor progression was also associated with collagen deposition (Figures 4A,C). This tissue remodeling also appeared to be progressively higher on the 28th day of tumor progression (Figure 4C). On day 14, collagen deposition was observed most frequently in peritumoral and necrotic areas and less frequently in the versican-expressing tumor stroma. On the other hand, tumors on day 28 presented higher amount of collagen deposited mainly in the tumor stroma, in addition to peritumoral and necrotic areas (Figure 4A). Versican expression intensity and percentage in neoplastic cells was positively associated with collagen deposition $(r=0.6619$, $P=0.0038$ and $r=0.6857, P=0.0024$, respectively), hemoglobin content $(r=0.7977, P=0.0002$ and $r=0.7882, P=0.0003$, respectively), and blood vessels $(r=0.8184, P<0.0001$ and $r=0.9352, P<0.0001$, respectively) (Table 1 ). The stromal versican expression intensity was found correlated with blood vessels $(r=0.6440, P=0.0053)$ and collagen deposition ( $r=0.5984, P=0.0087$ ), while no correlation was found between stromal versican staining percentage and angiogenesis markers and collagen deposition. These results collectively indicate tissue remodeling through the development of the 4T1 tumor model associated to higher versican expression and progressive deposition of collagen.

\section{Pulmonary Metastasis Is Positively Correlated With Versican Expression and Macrophage Accumulation During 4T1 Mammary Cancer Progression}

Lung metastasis was correlated with versican expression in the 4T1 primary tumor. As expected, an increasing number of metastatic nodules following tumor development were observed (Figures 5A,B). Lung samples collected on the 28th day-post transplant showed higher numbers of metastatic nodules when compared to the day $14(P<0.001)$ and day 


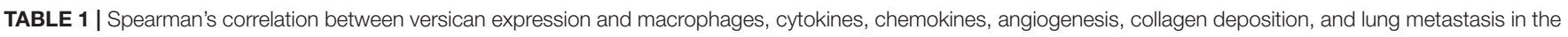
4T1 primary tumor.

\begin{tabular}{|c|c|c|c|c|c|c|c|c|}
\hline & \multicolumn{4}{|c|}{ Versican expression in stroma areas } & \multicolumn{4}{|c|}{ Versican expression in neoplastic cells } \\
\hline & \multicolumn{2}{|c|}{$\%$ Expression } & \multicolumn{2}{|c|}{ Intensity } & \multicolumn{2}{|c|}{ \% Expression } & \multicolumn{2}{|c|}{ Intensity } \\
\hline & $\begin{array}{l}\mathbf{R} \text { coefficient } \\
\text { value }\end{array}$ & $P$-value & $\begin{array}{c}R \text { coefficient } \\
\text { value }\end{array}$ & $P$-value & $\begin{array}{l}\mathbf{R} \text { coefficient } \\
\text { value }\end{array}$ & $P$-value & $\begin{array}{c}R \text { coefficient } \\
\text { value }\end{array}$ & $P$-value \\
\hline \multicolumn{9}{|l|}{ Macrophages } \\
\hline $\mathrm{F} 4 / 80$ & 0.3858 & 0.1731 & 0.3204 & 0.2444 & 0.6299 & $0.0158^{\star}$ & 0.7209 & $0.0036^{\star *}$ \\
\hline \multicolumn{9}{|c|}{ Cytokines and Chemokines } \\
\hline TNF- $\alpha$ & 0.3314 & 0.2099 & 0.5564 & $0.0204^{*}$ & 0.6730 & $0.0043^{\star \star}$ & 0.5649 & $0.0226^{*}$ \\
\hline VEGF & 0.5668 & $0.0220^{\star}$ & 0.6297 & $0.0067^{\star \star}$ & 0.8489 & $<0.0001^{\star \star \star}$ & 0.7600 & $0.0006^{\star * *}$ \\
\hline CCL2 & 0.5878 & $0.0166^{\star}$ & 0.6245 & $0.0074^{\star *}$ & 0.8853 & $0.0001^{\star * *}$ & 0.8229 & $<0.0001^{* * *}$ \\
\hline TGF- $\beta 1$ & 0.5715 & $0.0165^{\star}$ & 0.6440 & $0.0053^{\star *}$ & 0.3955 & 0.1043 & 0.5232 & $0.0311^{*}$ \\
\hline \multicolumn{9}{|c|}{ Angiogenesis and Collagen } \\
\hline Hemoglobin & 0.4604 & 0.7028 & 0.3914 & 0.1202 & 0.7882 & $0.0003^{\star \star \star}$ & 0.7977 & $0.0002^{\star * *}$ \\
\hline $\mathrm{N}^{\circ}$ of vessels & 0.4811 & 0.0592 & 0.6440 & $0.0053^{\star \star}$ & 0.9352 & $<0.0001^{* \star *}$ & 0.8184 & $<0.0001^{\star \star \star}$ \\
\hline Collagen deposition & 0.4379 & 0.0898 & 0.5984 & $0.0087^{\star \star}$ & 0.6857 & $0.0024^{\star *}$ & 0.6619 & $0.0038^{\star \star}$ \\
\hline \multicolumn{9}{|l|}{ Lung Metastasis } \\
\hline $\mathrm{N}^{\circ}$ metastatic nodules & 0.4135 & 0.1114 & 0.4476 & 0.0716 & 0.8495 & $<0.0001^{\star \star \star}$ & 0.7888 & $0.0003^{\star \star *}$ \\
\hline
\end{tabular}

TNF- $\alpha$, tumor necrosis factor- $\alpha$; VEGF, vascular growth factor; CCL2, CC motif chemokine ligand 2; TGF- $\beta 1$, tumor growth factor $B 1 .{ }^{*} P<0.05$, ${ }^{\star \star} P<0.01$, and ${ }^{\star \star \star} P<0.001$, respectively. The bold values mean results that are statistically significant.

A

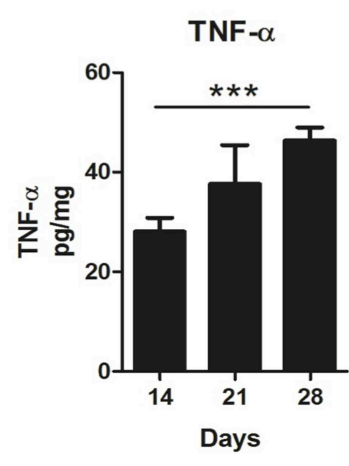

B

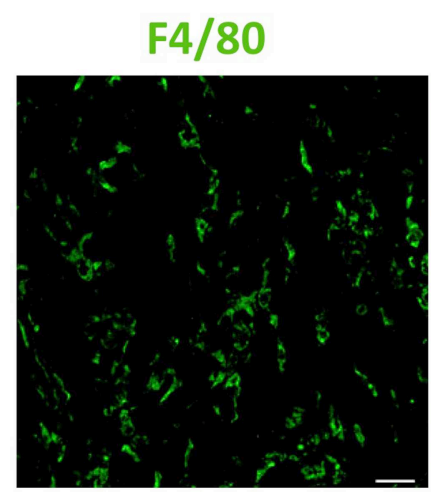

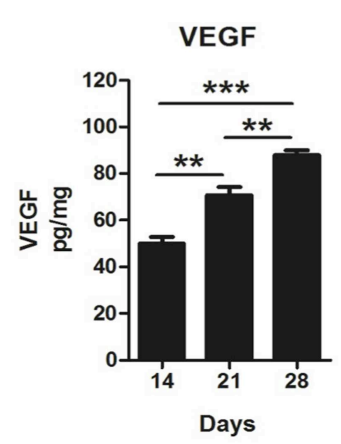

DAPI

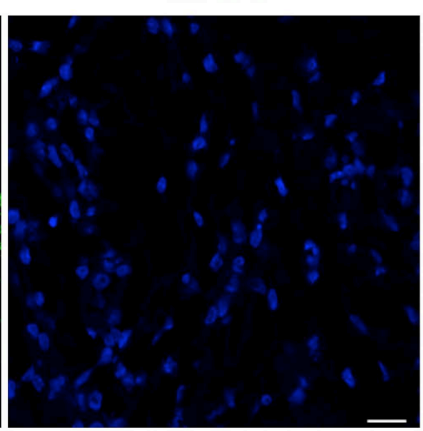

TGF- $\beta 1$

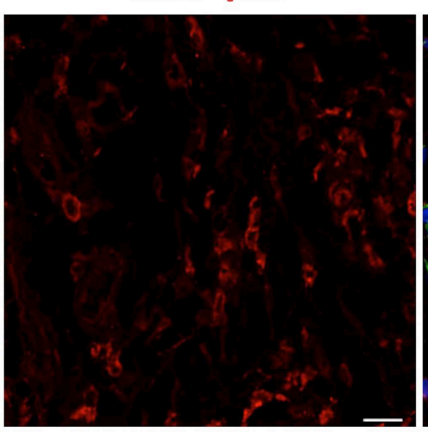

TGF $\beta 1$
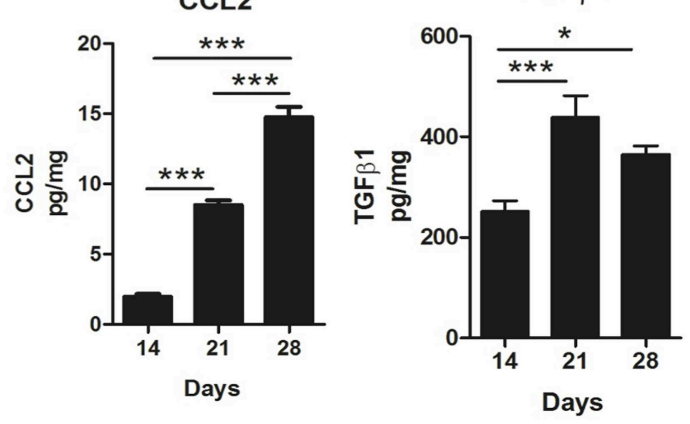

FIGURE 3 | Inflammatory milieu in primary tumors during 4T1 breast carcinoma progression in mice. Levels of TNF- $\alpha$, VEGF, CCL2, and TGF- $\beta 1$ were measured by enzyme-linked immunosorbent (ELISA) assay on the 14th, 21st, and 28th days post tumor transplant (A). One-way ANOVA test followed by Student-Newman-Keuls test was used to evaluate differences among groups. (B) Immunofluorescence staining of F4/80+ (green) and TGF- $\beta 1$ (red) in the peritumoral area of the $4 T 1$ primary tumor. Nuclei were counterstained with DAPI. Scale bars of $20 \mu \mathrm{m}$. Results are representative of two experiments and are shown as the mean \pm SEM of seven to eight animals in each group. ${ }^{\star} P<0.05,{ }^{\star \star} P<0.01$, and ${ }^{\star \star \star} P<0.001$, respectively. 


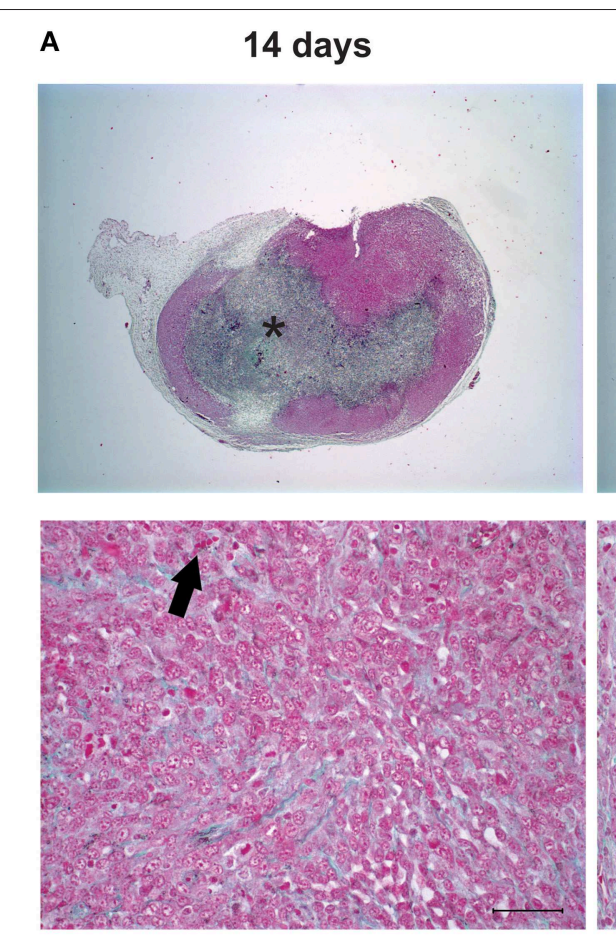

B

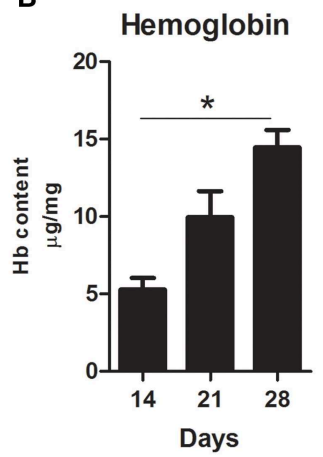

21 days
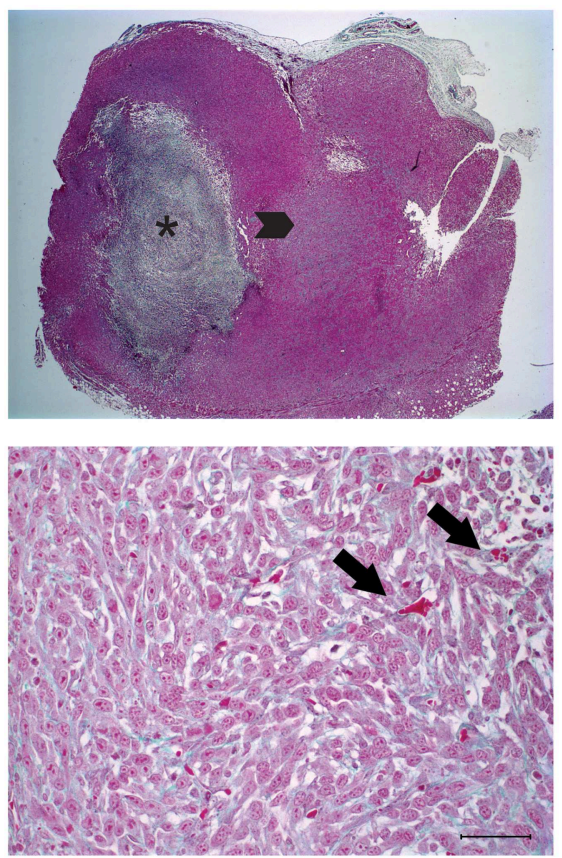

28 days
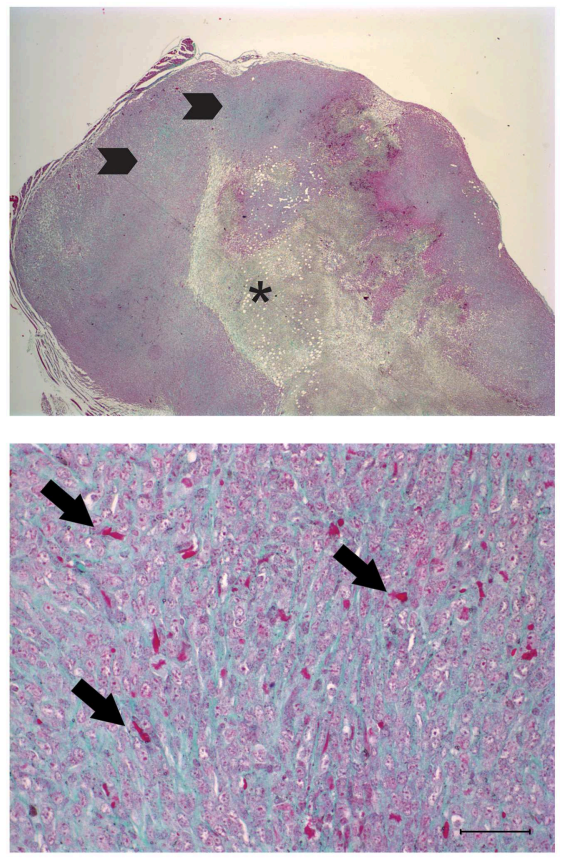

C
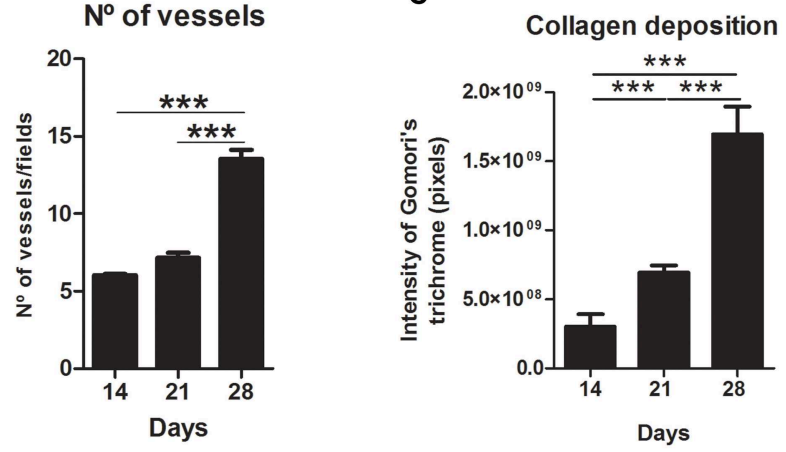

FIGURE 4 | Angiogenesis and tissue remodeling during 4T1 breast carcinoma progression in mice. Slides were stained with Gomori's trichrome to evaluate angiogenesis and collagen deposition on day 14, 21, and 28 of $4 \mathrm{~T} 1$ tumor development (A). Representative images show a progressive increase in blood vessels associated with 4T1 tumor progression, quantified in (B) trough hemoglobin content and vessel counting, and increased in collagen deposition, quantified in (C). Arrows (lower panel) represent blood vessels at different stages of tumor development. Note an increase in vessels density associated with the 4T1 tumor progression. Asterisks (upper panel) indicate central areas of necrosis with collagen deposition. Arrowheads (upper panel) represent collagen deposition in tumor areas. Note higher collagen deposition in tumoral areas at late stages. Scale bars of $50 \mu \mathrm{m}$. One-way ANOVA test followed by Student-Newman-Keuls test was used to evaluate differences among groups in (B). Results are representative of two experiments and are shown as the mean \pm SEM of seven to eight animals in each group. Kruskal-Wallis test followed by Dunn's multiple comparisons test was used to evaluate differences among groups in (C). ${ }^{\star} P<0.05$, ${ }^{* \star \star} P<0.001$, respectively.

$21(P<0.05)$ (Figures 5A,B). On the 28th day, all mice showed pulmonary metastasis, while only $37.5 \%(3 / 8)$ of day 21 mice presented pulmonary metastasis, and no pulmonary metastatic nodules were found in day 14 mice. Metastases were distributed throughout the lung parenchyma as nodules or small clusters of cells, mainly associated to vascular regions and pleura. Macrophage accumulation was also increased in the lung tissue in a time-dependent manner (Figure 5C). The expression of versican in neoplastic cells from primary tumors was strongly associated with the number of metastatic nodules in the lung (intensity score: $r=0.7888, P=0.0003$ and percentage score: $r=0.8495, P<0.0001$ ) (Table 1 ). Versican intensity in metastatic lung nodules was higher at day 28 when compared to day 14, while no difference was found regarding versican percentage (Figures 5D,E). Versican staining percentage in lung metastatic cells had a weak positive correlation with the number of metastatic nodules ( $r=0.7371, P=0.0370)$ (Table 2$)$. No correlation was observed between NAG levels and versican expression in lung metastasis (Table 2). 


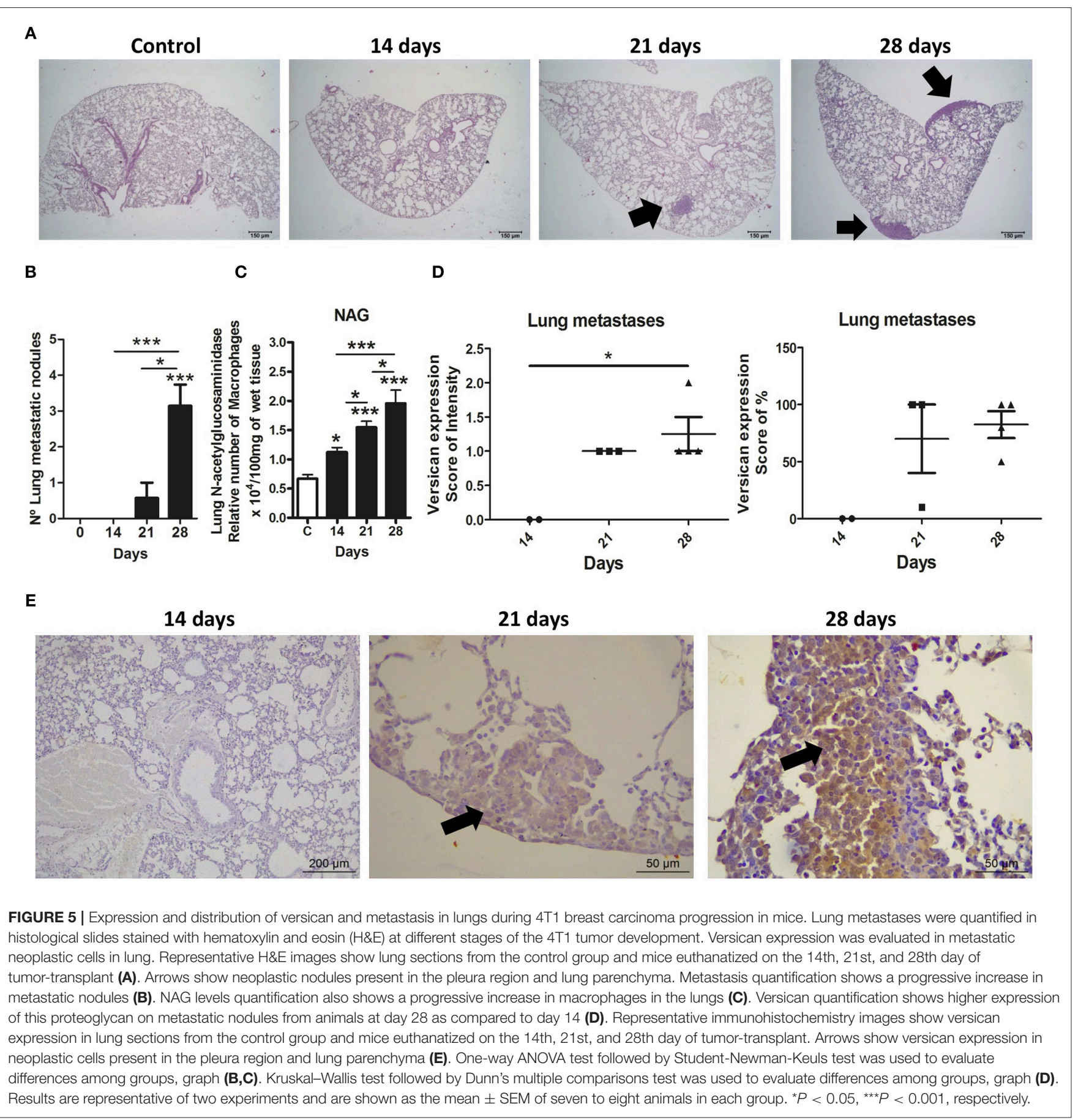

\section{High Versican Expression in Lung Parenchyma Was Associated With Progressive Leukocyte Influx and Pulmonary Dysfunction During \\ 4T1 Mammary Cancer Metastasis}

Cytokines and chemokines were measured in lung tissue (Figure 6A). CCL2 and CXCL1 peaks were detectable from day 21 , dropping slightly on day 28. VEGF was increased on days
14 and 21 , decreasing on day 2 . TGF- $\beta 1$ was found increased in all tumor-bearing mice when compared to the control animals. Versican staining intensity was correlated with CXCL1 $(r=0.6840, P=0.0422)$ and CCL2 $(r=0.7438, P=0.0216)$ levels in the lung parenchyma (Table 2). No association was observed between versican expression and VEGF or TGF- $\beta 1$ (Table 2).

Airway leukocyte influx was evaluated in BAL fluid, which revealed a progressive increase of leukocytes (Figure 6B) 
TABLE 2 | Spearman's correlation between versican expression and macrophages, cytokines, chemokines, and leukocytes in the 4T1 pulmonary metastases.

\begin{tabular}{|c|c|c|c|c|}
\hline & \multicolumn{4}{|c|}{ Versican expression in lung metastases } \\
\hline & \multicolumn{2}{|c|}{$\%$ Expression } & \multicolumn{2}{|c|}{ Intensity } \\
\hline & $\begin{array}{l}R \text { coefficient } \\
\text { value }\end{array}$ & $P$-value & $\begin{array}{l}R \text { coefficient } \\
\text { value }\end{array}$ & $P$-value \\
\hline \multicolumn{5}{|l|}{ Macrophages } \\
\hline NAG & 0.2394 & 0.5350 & 0.09405 & 0.8098 \\
\hline \multicolumn{5}{|c|}{ Cytokines and Chemokines } \\
\hline CXCL1 & 0.1539 & 0.6926 & 0.6840 & $0.0422^{*}$ \\
\hline VEGF & -0.2223 & 0.5654 & 0.5643 & 0.1135 \\
\hline CCL2 & 0.2223 & 0.5654 & 0.7438 & $0.0216^{*}$ \\
\hline TGF- $\beta 1$ & -0.5559 & 0.1950 & -0.3637 & 0.4226 \\
\hline \multicolumn{5}{|l|}{ BAL } \\
\hline Total cells & 0.3676 & 0.3304 & 0.3505 & 0.3550 \\
\hline Eosinophils & 0.4873 & 0.1833 & -0.4446 & 0.2305 \\
\hline Neutrophils & 0.3762 & 0.3184 & 0.1624 & 0.6763 \\
\hline Macrophages & 0.4959 & 0.1746 & 0.5899 & 0.0945 \\
\hline Lymphocytes & 0.2052 & 0.5964 & 0.2137 & 0.5808 \\
\hline \multicolumn{5}{|l|}{ Lung Metastasis } \\
\hline $\mathrm{N}^{\circ}$ metastatic nodules & 0.7371 & $0.0370^{*}$ & 0.2017 & 0.6319 \\
\hline
\end{tabular}

NAG, $N$-acetyl- $\beta$-D-glucosaminidase; CXCL1, chemokine (C-X-C motif) ligand 1; VEGF, vascular growth factor; CCL2, CC motif chemokine ligand 2; TGF- $\beta 1$, tumor growth factor B1; BAL, bronchoalveolar lavage. ${ }^{\star} P<0.05,{ }^{\star \star \star} P<0.001$, respectively. The bold values mean results that are statistically significant.

associated to tumor development and metastasis. All inflammatory cell types were increased in BAL at days 14, 21 , and 28 when compared to the control. Day 14 was marked by a predominance of macrophage, and neutrophil, eosinophil and lymphocyte influx on days 21 and 28 (Figure 6B). Moreover, total leukocytes peaked on day 28 when compared to day 14 and 21 , with a predominance of macrophages and eosinophils during late stages of metastatic progression (Figure 6B). No association was observed between versican expression in metastatic nodules and leukocytes presented in BAL.

A forced spirometry technique was used to evaluate the physiological changes in lung function caused by the metastatic development and versican accumulation in lung parenchyma during 4T1 breast cancer metastasis. High versican expression in parallel with metastatic progression leads to a progressive decline in pulmonary function, mainly highlighted on day 28 , evidenced by volume loss, such as reduction in FVC, FRC, RV (Figure 7A), and the Pressure $\times$ Volume curve (Figure 7B). In addition, the mice presented a time-dependent decline in respiratory airway flow, with a decrease in FEV50 and in FEV100 (Figure 7C), confirmed by the Flow $\times$ Volume curve, when compared to the control animals (Figure 7D). Moreover, the day 28 animals presented a greater restrictive behavior of the respiratory airway flow, evidenced by the Tiffeneau-Pinelli index (Figure 7C). Regarding pulmonary elasticity, through analysis of lung compliance (Cdyn) and resistance (Rl), animals transplanted with the $4 \mathrm{~T} 1$ tumors exhibited a reduction in dynamic compliance, with a significant increase in resistance on day 28 when compared to control animals (Figure 7E).
Collectively, our data suggests that the lost pulmonary function may is a result from the accumulation of pulmonary metastatic nodes on day 28 .

\section{DISCUSSION}

Versican expression has been linked with poor prognosis and relapse-free survival in cancer patients $(15,41,42)$. Interaction among versican, ECM components, and neoplastic cells are recognized as regulators of proliferation and metastatic potential $(16,43,44)$. Indeed, immune cells, mostly macrophages, have an important role in ECM remodeling, including regulation of versican levels and, consequently, tumor progression $(3,44)$. A previous study described the interaction of versican with TAMs, promoting their activation, migration, and production of growth factors (20). However, in the context of breast cancer, the most common cancer in women worldwide and cancer-related deaths in women (7), the role of versican remains unexplored. Here we highlighted the correlation between versican expression, TAMs accumulation and tumor progression using two models of mammary carcinomas: spontaneous mammary carcinoma in dogs and mammary carcinoma implanted in mice. Naturally occurring cancers in canines and humans share many features, including tumor phenotype, genetic markers and molecular targets (45). Thus, studying the cancer development in canines and rodents may provide a valuable perspective, potentially useful for diagnosis and therapeutics in humans.

The tumor microenvironment is an important participant of tumor progression and metastasis (3). TAMs are important in the context of tumor biology, involved in both invasiveness and metastatization (21-23), with M2-polarized macrophages characterized as promoters of angiogenesis, epithelialmesenchymal transition and tissue remodeling in cancer manifestation (27). We showed that TAMs were predominately localized in the peripheral areas of primary tumors, with their increase associated to stromal versican expression, as observed by Asano et al. (46). M2-polarized macrophages have been showed to produce large quantities of soluble mediators in the tumor microenvironment such as CCL2, VEGF, and TGF- $\beta 1$ that interact with neoplastic cells promoting their proliferation and invasion (47-51). However, we found increased levels of CCL2, VEGF, and TGF- $\beta 1$ also positively correlating with $\mathrm{F} 4 / 80+$ macrophages, high vascularization and collagen deposition during tumor progression in the 4T1 mouse model. These macrophages are the source of TGF- $\beta 1$, as confirmed by microscopy. TAMs can also induce tumor angiogenesis, and have been involved in collagen deposition and linearization of the tumor stroma in more aggressive human breast cancer subtypes (8). Accordingly, we revealed that the 4T1 development evolved in a TAM-derived inflamed milieu and neovascularized tumor tissue, with increased collagen deposition in the tumor microenvironment. Collectively, these findings indicate that the 4T1 tumor progression is related with peritumoral TAM infiltration and may promote the gradual replacement of extracellular matrix and angiogenesis through its cytokines production. 


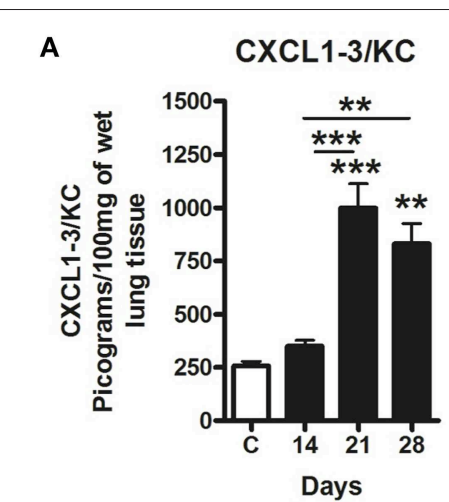

B

Total cells

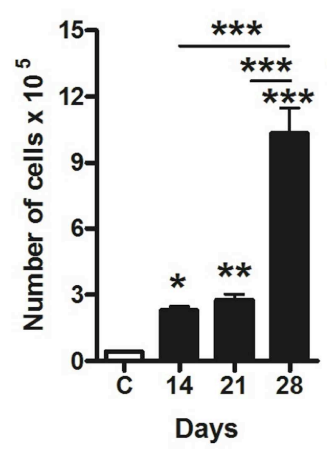

Macrophages

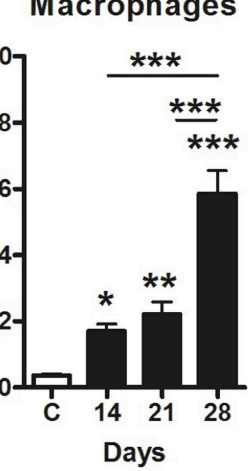

CCL2/MCP-1

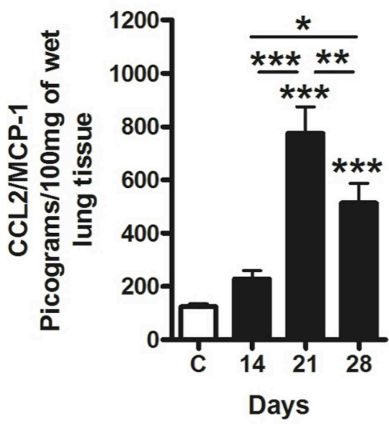

VEGF

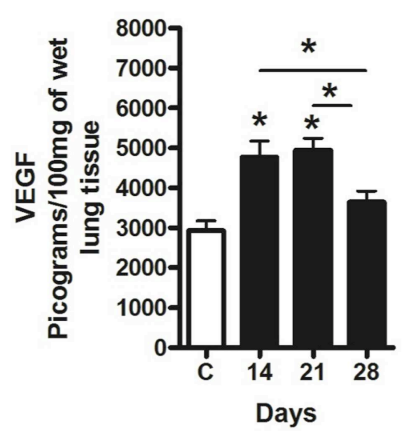

TGF- $\beta 1$

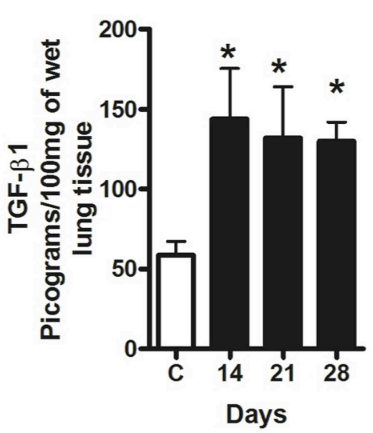

FIGURE 6 | Pulmonary inflammation related to 4T1 mammary carcinoma metastasis progression in mice. Inflammation was evaluated in BAL and differential leukocyte counts and ELISA assays in the lungs samples. Levels of CXCL1, CCL2, VEGF, and TGF- $\beta 1$ were measured by ELISA assay on the 14 th, 21 st, and 28 th days post tumor transplant (A). BAL counts shows a progressive leukocyte infiltration following metastatic development of the 4T1 tumor, with a predominance of macrophages in BAL in late time-points, when compared to Control group (B). One-way ANOVA test followed by Student-Newman-Keuls test was used to evaluate differences among groups. Results are representative of two experiments and are shown as the mean \pm SEM of seven to eight animals in each group. ${ }^{\star} P<0.05$, ${ }^{* \star} P<0.01$, and ${ }^{* *} P<0.001$, respectively.

Versican, an extracellular matrix proteoglycan, is also involved in TAM activation through TLRs, inducing the production of pro-inflammatory and pro-tumoral cytokines and chemokines, in addition to versican production (17-20, 50). In fact, these interactions between tissue microenvironment and parenchymal cells are detrimental for the maintenance of cancer progression and invasiveness. In breast cancer, the interaction between stromal versican deposition and neoplastic cells was previously shown as an important step in tumorigenesis (46). However, the authors described low proteoglycan expression in the cells, possibly justified by the secretion of soluble mediators by other cells, leading to an increase in the deposition of versican by fibroblasts during neoplastic extracellular matrix remodeling. Besides fibroblasts, macrophages have also been demonstrated to produce versican in different murine tumor models (46).

Breast cancer metastasizes through lymphatic and blood vessels mainly to lymph nodes, lungs, bones, liver, and brain $(52,53)$. The onset of metastasis in the $4 \mathrm{~T} 1$ tumor often occurs after the second week post-transplant (54). In the present study, versican expression was observed in neoplastic cells and peripheral areas in all studied time-points. The metastatic progression of the $4 \mathrm{~T} 1$ tumor was accompanied by the up-regulation of versican expression in neoplastic cells of the primary tumor, which was correlated with the number of pulmonary metastatic nodules. In fact, overexpression of versican has been showed to increase growth, proliferation and metastatic potential of a breast cancer murine model (43), while the versican silencing exerted an inhibitory effect on the proliferative and migratory ability of melanoma cells (55). Thus, since versican was differentially expressed in peripheral and tumor areas, we suggest a pro-tumoral role of versican, promoting tumor progression and metastasis of the $4 \mathrm{~T} 1$ tumor model.

Versican has been shown to interact with myeloid and lymphoid cells in the tumor microenvironment, promoting their adhesion and production of inflammatory cytokines that may trigger the tumor invasion $(11,16,19,56,57)$. Thus, the proteoglycan versican may interact with leukocytes and neoplastic cells to establish a microenvironment that favors tumor expansion in the context of the 4T1 model. Increased cytokines and chemokines, such as TGF- $\beta 1$, CCL2, and VEGF, have been shown to predict metastatic disease $(50,51,53)$. Furthermore, TGF- $\beta 1$ has been shown to upregulate the production of versican in cancer cells and the tumor stroma, resulting in invasiveness and metastasis (39, 40, 

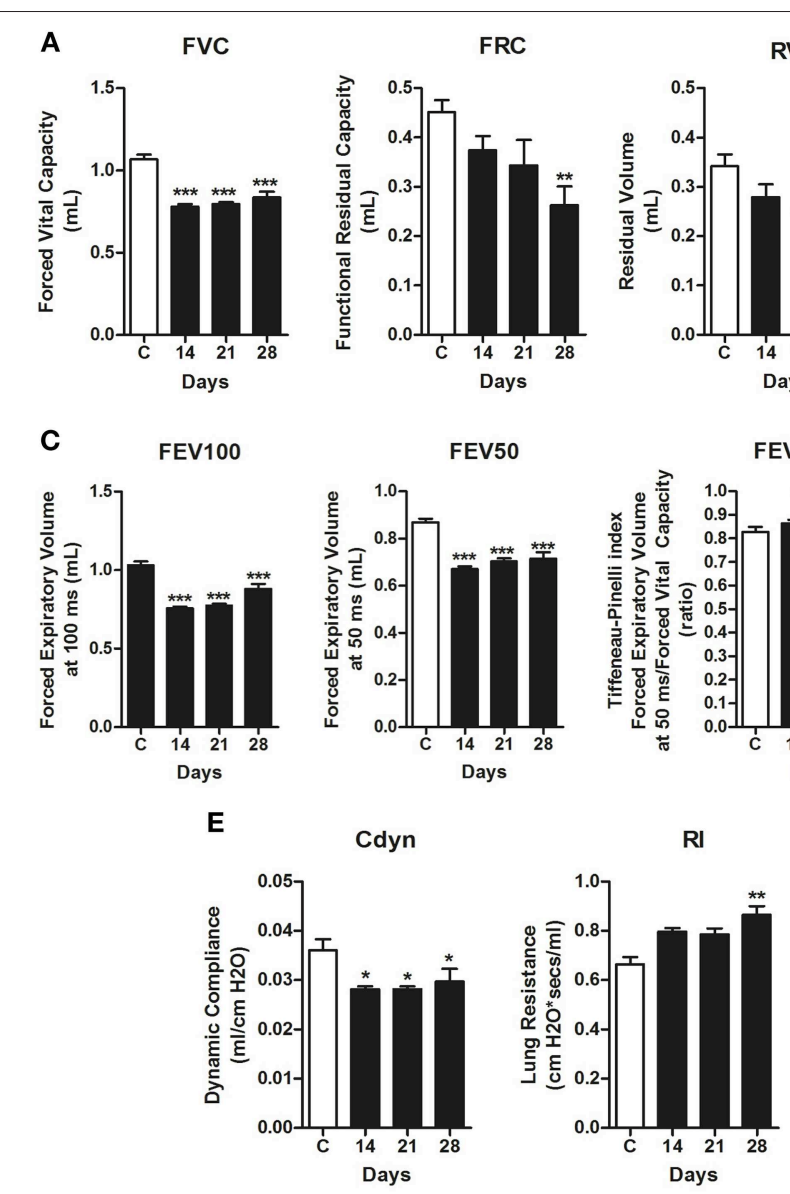

B
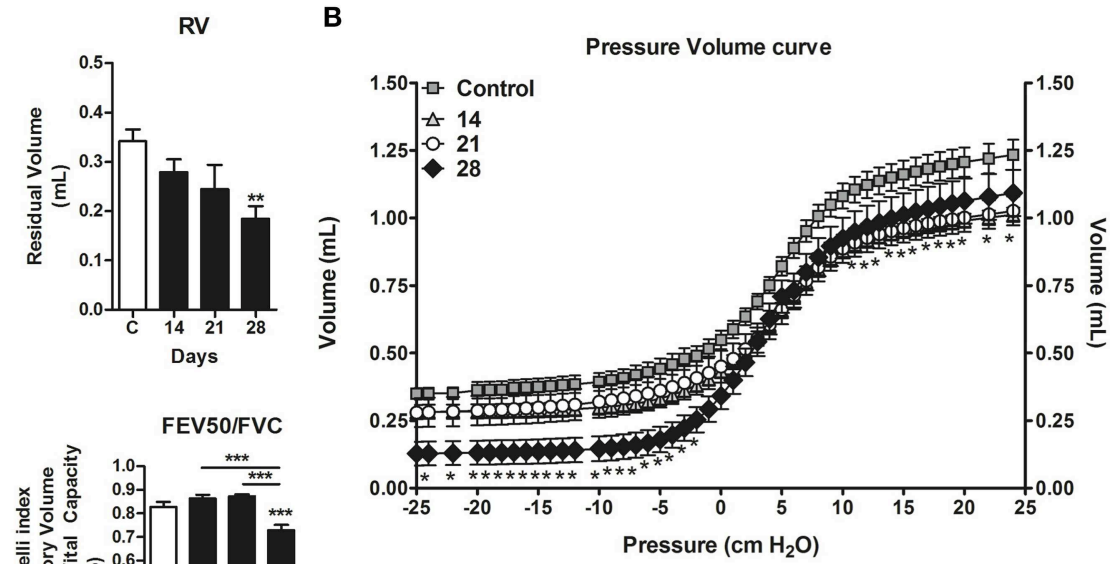

D
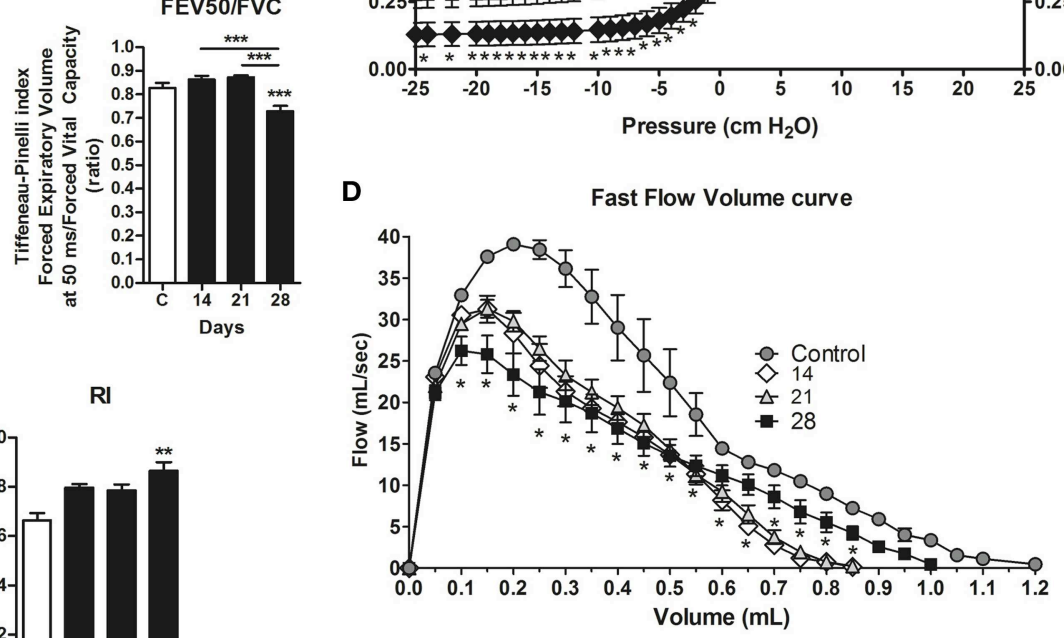

FIGURE 7 | Assessment of pulmonary mechanic functions at different stages of lung metastasis during 4T1 breast carcinoma metastasis progression in mice. Invasive spirometry was performed to investigate functional modifications in pulmonary mechanics. The parameters assessed were: Lung volumes (A), depicted by Forced Vital Capacity, Functional Residual Capacity, and Residual Volume; Pressure $\times$ Volume Curve (B); Airway flow (C) by Forced Expiratory Volume, Forced Expiratory Volume at $50 \mathrm{~ms}$, and Tiffeneau-Pinelli index; Fast Flow Volume Curve (D); Lung elasticity (E) by Dynamic Compliance Forced and Lung Resistance. Kruskal-Wallis test followed by Dunn's multiple comparisons test was used to evaluate differences among groups. Results are shown as the mean \pm SEM. ${ }^{\star} P<0.05$; ${ }^{\star *} P<0.01 ;{ }^{* *} P<0.001$, respectively.

49). We found a marked production of CCL2 and CXCL1 in the lung, in parallel with macrophage influx, increased metastatic disease and high versican expression in the lung tissue. These chemokines are related to leukocyte recruitment and angiogenesis, which could contribute toward a pro-metastatic pulmonary microenvironment, directly stimulate the tumor progression and metastasis.

Lung metastasis may affect pulmonary microenvironment and function (10). The progression of the 4T1 breast cancer model resulted in an increased leukocyte influx in the airways, mostly composed by macrophages, also associated to a higher number of metastatic nodules and infiltrating TAMs. Pulmonary mechanical functions were altered during tumor progression. This alteration was evidenced even on day 14, when metastatic nodules were absent, and progressed to more pronounced lung dysfunction on day 28. Our data corroborates that pulmonary versican expression is associated to metastatic nodules, inflammation and alveolar edema, which impacts lung dysfunction, preceding mortality. Moreover, the number of metastatic nodes in the lung leads to a greater restrictive behavior of the respiratory airway flow in mice. Finally, future studies using cytokinesand versican-knockdown mice and macrophage-depleted mice could better explore the relationship between TAMs and versican in the metastatic development of $4 \mathrm{~T} 1$ breast cancer mice model.

In conclusion, stromal versican expression was found in primary canine and murine breast cancer models. Increased versican expression correlates with elevated TAMs infiltration in the primary tumor preceding the metastatic progression in mice. Versican expression also correlates with increase metastasis and pulmonary dysfunction, suggesting the involvement of TAMs in regulating important steps during murine $4 \mathrm{~T} 1$ breast cancer model development through versican signaling. Therefore, versican and TAMs might represent an attractive target for breast cancer therapy. 


\section{ETHICS STATEMENT}

Canine mammary tumors samples: All procedures were performed under the guidelines and with the approval of the Ethics Committee in Animal Experimentation (CETEA/UFMG), protocol 219/2009 and 81/2013). Murine 4T1 breast cancer model: All research was conducted under a protocol approved (number 262/2012) by an Ethics Committee on Animal Use (CEUA) from Federal University of Minas Gerais, Brazil.

\section{AUTHOR CONTRIBUTIONS}

GC, RR, and DdR designed the research. DdR performed in vivo experiments, histology image analysis, and data analysis. KD performed immunohistochemistry, score, and analyses of versican and macrophages in canine samples. $\mathrm{EV}$ and GP maintained the $\mathrm{BALB} / \mathrm{c}$ mice used in the experiments and performed mouse necropsies. LK, MM, and PC performed BAL, cytokines, and chemokines dosages. RR executed and analyzed forced spirometry data. MR

\section{REFERENCES}

1. Lu P, Weaver VM, Werb Z. The extracellular matrix: a dynamic niche in cancer progression. J Cell Biol. (2012) 196:395-406. doi: 10.1083/jcb.201102147

2. Artacho-Cordón A, Artacho-Cordón F, Ríos-Arrabal S, Calvente I, Núñez MI. Tumor microenvironment and breast cancer progression: a complex scenario. Cancer Biol Ther. (2012) 13:14-24. doi: 10.4161/cbt.13.1.18869

3. Quail D, Joyce J. Microenvironmental regulation of tumor progression and metastasis. Nat Med. (2013) 19:1423-37. doi: 10.1038/nm.3394

4. Damasceno KA, Bertagnolli AC, Estrela-Lima A, Rabelo BS, Campos LC, Ribeiro LGR, et al. Versican expression in myoepithelial cells from carcinomas in canine mixed mammary tumors. Vet J. (2014) 200:146-51. doi: 10.1016/j.tvjl.2014.01.013

5. Naba A, Clauser KR, Lamar JM, Carr SA, Hynes RO. Extracellular matrix signatures of human mammary carcinoma identify novel metastasis promoters. Elife. (2014) 2014:e01308. doi: 10.7554/eLife.01308

6. Balkwill FR, Capasso M, Hagemann T. The tumor microenvironment at a glance. J Cell Sci. (2012) 125:5591-6. doi: 10.1242/jcs.116392

7. Hashim D, Boffetta P, La Vecchia C, Rota M, Bertuccio P, Malvezzi M, et al. The global decrease in cancer mortality: trends and disparities. Ann Oncol. (2016) 27:926-33. doi: 10.1093/annonc/mdw027

8. Acerbi I, Cassereau L, Dean I, Shi Q, Au A, Park C, et al. Human breast cancer invasion and aggression correlates with ECM stiffening and immune cell infiltration. Integr Biol. (2015) 7:1120-34. doi: 10.1039/c5ib00040h

9. Wu Q, Li J, Zhu S, Wu J, Chen C, Liu Q, et al. Breast cancer subtypes predict the preferential site of distant metastases: a SEER based study. Oncotarget. (2017) 8:27990-6. doi: 10.18632/oncotarget.15856

10. Lee JH, Song EM, Sim YS, Ryu YJ, Chang JH. Forced expiratory volume in one second as a prognostic factor in advanced non-small cell lung cancer. J Thorac Oncol. (2011) 6:305-9. doi: 10.1097/JTO.0b013e318201884b

11. Wight TN, Kinsella MG, Evanko SP, Potter-Perigo S, Merrilees MJ. Versican and the regulation of cell phenotype in disease. Biochim Biophys Acta. (2014) 1840:2441-51. doi: 10.1016/j.bbagen.2013.12.028

12. Andersson-Sjöland A, Hallgren O, Rolandsson S, Weitoft M, Tykesson E, Larsson-Callerfelt A-K, et al. Versican in inflammation and tissue remodeling: the impact on lung disorders. Glycobiology. (2014) 25:1-9. doi: $10.1093 /$ glycob/cwu120

13. Kischel P, Waltregny D, Dumont B, Turtoi A, Greffe Y, Kirsch S, et al. Versican overexpression in human breast cancer lesions: known and new isoforms for stromal tumor targeting. Int J Cancer. (2010) 126:640-50. doi: $10.1002 /$ ijc. 24812 and DG were responsible by confocal image. DdR, KD, CdC, EF, RR, and GC drafted the work. GC and RR supervised the study and final approval of the version to be published.

\section{FUNDING}

This work was supported in part by Conselho Nacional de Desenvolvimento Científico e Tecnológico (CNPq) and Coordenação de Aperfeiçoamento de Pessoal de Nível Superior (CAPES).

\section{ACKNOWLEDGMENTS}

Pró-Reitoria de Pesquisa da Universidade Federal de Minas Gerais-UFMG/EDITAL PRPq-02/2019. The microscopic data shown in this work was obtained using the microscopes of Centro de Aquisição e Processamento de Imagens (CAPI-ICB/UFMG). We are grateful to Prof. Mauro Martins Teixeira for assistance and support during this work.

14. Du WW, Yang W, Yee AJ. Roles of versican in cancer biologytumorigenesis, progression and metastasis. Histol Histopathol. (2013) 28:70113. doi: 10.14670/HH-28.701.

15. Shen X, Lin W, Xu M, Qi P, Dong L, Zhang Q, et al. Prognostic significance of Versican expression in gastric adenocarcinoma. Oncogenesis. (2015) 4:e178. doi: 10.1038/oncsis.2015.36

16. Ricciardelli C, Sakko AJ, Ween MP, Russell DL, Horsfall DJ. The biological role and regulation of versican levels in cancer. Cancer Metastasis Rev. (2009) 28:233-45. doi: 10.1007/s10555-009-9182-y

17. Chang MY, Chan CK, Braun KR, Green PS, O'Brien KD, Chait A, et al. Monocyte-to-macrophage differentiation: synthesis and secretion of a complex extracellular matrix. J Biol Chem. (2012) 287:14122-35. doi: 10.1074/jbc.M111.324988

18. Masuda A, Yasuoka H, Satoh T, Okazaki Y, Yamaguchi Y, Kuwana M. Versican is upregulated in circulating monocytes in patients with systemic sclerosis and amplifies a CCL2-mediated pathogenic loop. Arthritis Res Ther. (2013) 15:R74. doi: 10.1186/ar4251

19. Wight TN, Kang I, Merrilees MJ. Versican and the control of inflammation. Matrix Biol. (2014) 35:152-61. doi: 10.1016/j.matbio.2014.01.015

20. Kim S, Takahashi H, Lin W-W, Descargues P, Grivennikov S, Kim Y, et al. Carcinoma-produced factors activate myeloid cells through TLR2 to stimulate metastasis. Nature. (2009) 457:102-6. doi: 10.1038/nature07623

21. Biswas SK, Allavena P, Mantovani A. Tumor-associated macrophages: functional diversity, clinical significance, and open questions. Semin Immunopathol. (2013) 35:585-600. doi: 10.1007/s00281-013-0367-7

22. Cook J, Hagemann T. Tumour-associated macrophages and cancer. Curr Opin Pharmacol. (2013) 13:595-601. doi: 10.1016/j.coph.2013.05.017

23. Cortez-Retamozo V, Etzrodt M, Newton A, Rauch PJ, Chudnovskiy A, Berger C, et al. Origins of tumor-associated macrophages and neutrophils. Proc Natl Acad Sci USA. (2012) 109:2491-6. doi: 10.1073/pnas.1113744109

24. Siveen KS, Kuttan G. Role of macrophages in tumour progression. Immunol Lett. (2009) 123:97-102. doi: 10.1016/j.imlet.2009.02.011

25. Hembruff SL, Jokar I, Yang L, Cheng N. Loss of transforming growth factor-beta signaling in mammary fibroblasts enhances CCL2 secretion to promote mammary tumor progression through macrophagedependent and -independent mechanisms. Neoplasia. (2010) 12:425-33. doi: $10.1593 /$ neo. 10200

26. Guo C, Buranych A, Sarkar D, Fisher PB, Wang X-Y. The role of tumorassociated macrophages in tumor vascularization. Vasc Cell. (2014) 6:2. doi: $10.1186 / 2045-824 \mathrm{X}-6-2$ 
27. Mantovani A, Sica A. Macrophages, innate immunity and cancer: balance, tolerance, and diversity. Curr Opin Immunol. (2010) 22:231-7. doi: 10.1016/j.coi.2010.01.009

28. Misdorp W, Else RW, Hellmén E, Lipscomb TP. Histological classification of Mammary Tumors of the Dog and the Cat. Vol. VII. 2nd Series. Washington, DC: Armed Forces Institute of Pathology; American Registry of Pathology and the World Health Organization Collaborating Center for Worldwide Reference on Comparative Oncology (1999). p. 1-59.

29. Cassali GD, Lavalle GE, Ferreira E, Estrela-Lima A, De Nardi AB, Ghever $\mathrm{C}$, et al. Consensus for the diagnosis, prognosis and treatment of canine mammary tumors - 2013. Braz J Vet Pathol. (2014) 7:38-69.

30. Elston CW, Ellis IO. Assessment of histological grade. In: Elston CW, Ellis IO, editors. Systemic Pathology: The Breast. 3rd ed. London: Churchill Livingstone (1998). p. 365-84.

31. Owen LM. TNM Classification of Tumours in Domestic Animals. Geneva: World Health Organization (1980). p. 53.

32. Russo RC, Savino B, Mirolo M, Buracchi C, Germano G, Anselmo A, et al. The atypical chemokine receptor ACKR2 drives pulmonary fibrosis by tuning influx of CCR2+ and CCR5+ IFN $\gamma$-producing $\gamma \delta$ T cells in mice. Am J Physiol Cell Mol Physiol. (2018) 314:L1010-25. doi: 10.1152/ajplung.00233.2017

33. Russo RC, Garcia CC, Barcelos LS, Rachid MA, Guabiraba R, Roffê E, et al. Phosphoinositide 3-kinase $\gamma$ plays a critical role in bleomycin-induced pulmonary inflammation and fibrosis in mice. J Leukoc Biol. (2011) 89:269-82. doi: $10.1189 /$ jlb.0610346

34. Monteiro LN, Rodrigues MA, Gomes DA, Salgado BS, Cassali GD. Tumourassociated macrophages: relation with progression and invasiveness, and assessment of M1/M2 macrophages in canine mammary tumours. Vet J. (2018) 234:119-25 doi: 10.1016/j.tvjl.2018.02.016

35. Skandalis SS, Labropoulou VT, Ravazoula P, Likaki-Karatza E, Dobra K, Kalofonos HP, et al. Versican but not decorin accumulation is related to malignancy in mammographically detected high density and malignantappearing microcalcifications in non-palpable breast carcinomas. BMC Cancer. (2011) 11:314. doi: 10.1186/1471-2407-11-314

36. Russo RC, Alessandri AL, Garcia CC, Cordeiro BF, Pinho V, Cassali GD, et al. Therapeutic effects of evasin-1, a chemokine binding protein, in bleomycininduced pulmonary fibrosis. Am J Respir Cell Mol Biol. (2011) 45:72-80. doi: 10.1165/rcmb.2009-0406OC

37. Ferreira MAND, Barcelos LS, Teixeira MM, Bakhle YS, Andrade SP. Tumor growth, angiogenesis and inflammation in mice lacking receptors for platelet activating factor (PAF). Life Sci. (2007) 81:210-7. doi: 10.1016/j.lfs.2007.05.003

38. Gamba CO, Rodrigues MA, Gomes DA, Estrela-Lima A, Ferreira E, Cassali GD. The relationship between E-cadherin and its transcriptional repressors in spontaneously arising canine invasive micropapillary mammary carcinoma. $J$ Comp Pathol. (2015) 153:256-65. doi: 10.1016/j.jcpa.2015.08.006

39. Norian JM, Malik M, Parker CY, Joseph D, Leppert PC, Segars JH, et al. Transforming growth factor $\beta 3$ regulates the versican variants in the extracellular matrix-rich uterine leiomyomas. Reprod Sci. (2009) 16:1153-64. doi: $10.1177 / 1933719109343310$

40. Yeung TL, Leung CS, Wong KK, Samimi G, Thompson MS, Liu J, et al. TGF- $\beta$ modulates ovarian cancer invasion by upregulating CAF- derived versican in the tumor microenvironment. Cancer Res. (2013) 73:5016-28. doi: 10.1158/0008-5472.CAN-13-0023

41. Ricciardelli C, Brooks JH, Suwiwat S, Sakko AJ, Mayne K, Raymond WA, et al. Regulation of stromal versican expression by breast cancer cells and importance to relapse-free survival in patients with node-negative primary breast cancer. Clin Cancer Res. (2002) 8:1054-60.

42. Pukkila M, Kosunen A, Ropponen K, Virtaniemi J, Kellokoski J, Kumpulainen E, et al. High stromal versican expression predicts unfavourable outcome in oral squamous cell carcinoma. J Clin Pathol. (2006) 60:267-72. doi: $10.1136 /$ jcp.2005.034181
43. Du WW, Fang L, Yang X, Sheng W, Yang BL, Seth A, et al. The role of versican in modulating breast cancer cell self-renewal. Mol Cancer Res. (2013) 11:443-55. doi: 10.1158/1541-7786.MCR-12-0461

44. Laoui D, Movahedi K, Van Overmeire E, Van den Bossche J, Schouppe E, Mommer C, et al. Tumor-associated macrophages in breast cancer: distinct subsets, distinct functions. Int J Dev Biol. (2011) 55:861-7. doi: $10.1387 / \mathrm{ijdb} .113371 \mathrm{dl}$

45. Paoloni M, Khanna C. Translation of new cancer treatments from pet dogs to humans. Nat Rev Cancer. (2008) 8:147-56. doi: 10.1038/nrc2273

46. Asano K, Nelson CM, Nandadasa S, Aramaki-Hattori N, Lindner DJ, Alban T, et al. Stromal versican regulates tumor growth by promoting angiogenesis. Sci Rep. (2017) 7:1-11. doi: 10.1038/s41598-017-17613-6

47. Oktem G, Sercan O, Guven U, Uslu R, Uysal A, et al. Cancer stem cell differentiation: TGF $\beta 1$ and versican may trigger molecules for the organization of tumor spheroids. Oncol Rep. (2014) 32:641-9. doi: 10.3892/or.2014.3252

48. Li S, Li F, Cheng T. TGF- $\beta 1$ promotes osteosarcoma cell migration and invasion through the miR-143-versican pathway. Cell Physiol Biochem. (2014) 34:2169-79. doi: 10.1159/000369660

49. Curran CS, Keely PJ. Breast tumor and stromal cell responses to TGF$\beta$ and hypoxia in matrix deposition. Matrix Biol. (2013) 32:95-105. doi: 10.1016/j.matbio.2012.11.016

50. Conti I, Rollins BJ. CCL2 (monocyte chemoattractant protein-1) and cancer. Semin Cancer Biol. (2004) 14:149-54. doi: 10.1016/j.semcancer.2003. 10.009

51. Soria G, Ben-Baruch A. The inflammatory chemokines CCL2 and CCL5 in breast cancer. Cancer Lett. (2008) 267:271-85. doi: 10.1016/j.canlet.2008.03.018

52. Minn AJ, Gupta GP, Siegel PM, Bos PD, Shu W, Giri DD, et al. Genes that mediate breast cancer metastasis to lung. Nature. (2005) 436:518-24. doi: 10.1038/nature03799

53. Rahman M, Mohammed S. Breast cancer metastasis and the lymphatic system (Review). Oncol Lett. (2015) 10:1233-9. doi: 10.3892/ol.2015.3486

54. Pulaski BA, Ostrand-Rosenberg S. Mouse 4T1 breast tumor model. Curr Protoc Immunol. (2001) Chapter 20:Unit 20.2. doi: 10.1002/0471142735.im2002s39

55. Wang Z, Li Z1, Wang Y, Cao D, Wang X, Jiang M, et al. Versican silencing improves the antitumor efficacy of endostatin by alleviating its induced inflammatory and immunosuppressive changes in the tumor microenvironment. Oncol Rep. (2015) 33:2981-91. doi: 10.3892/or.2015.3903

56. Schmitt M. Versican vs. versikine: tolerance vs. attack. Blood. (2016) 128:612-3. doi: 10.1182/blood-2016-06 721092

57. Fu Y, Nagy JA, Brown LF, Shih SC, Johnson PY, Chan CK, et al. Proteolytic cleavage of versican and involvement of ADAMTS-1 in VEGF-A/VPFinduced pathological angiogenesis. J Histochem Cytochem. (2011) 59:463-73. doi: $10.1369 / 0022155411401748$

Conflict of Interest Statement: The authors declare that the research was conducted in the absence of any commercial or financial relationships that could be construed as a potential conflict of interest.

Copyright (C) 2019 dos Reis, Damasceno, de Campos, Veloso, Pêgas, Kraemer, Rodrigues, Mattos, Gomes, Campos, Ferreira, Russo and Cassali. This is an openaccess article distributed under the terms of the Creative Commons Attribution License (CC BY). The use, distribution or reproduction in other forums is permitted, provided the original author(s) and the copyright owner(s) are credited and that the original publication in this journal is cited, in accordance with accepted academic practice. No use, distribution or reproduction is permitted which does not comply with these terms. 